\title{
Evaluation of Antioxidant Properties of Allium Cepa Fruits and Ocimum Basilicum Leaves
}

\author{
Srividya L* and Reddy ARN \\ Department of Pharma Analysis \& Quality Assurance, Jyothishmathi Institute of \\ Pharmaceutical Sciences, Karimnagar, India
}

*Corresponding author: Srividya Lonkala, Associate Professor \& HOD, Department of

Research Article

Volume 2 Issue 8

Received Date: June 15, 2018

Published Date: July 20, 2018

Pharma Analysis \& Quality Assurance, Jyothishmathi Institute of Pharmaceutical Sciences, Karimnagar, India, Tel: +91 9493472098; Email: svps11288@gmail.com

\begin{abstract}
In the present study research was carried out on the compound extracted from Ocimum basilicum leaves and Allium cepa fruits have antioxidant properties and this effect is increased by increasing the quantity of this compound, which can be used as an alternative for novel medicine. The crude fruits and leaves were collected from local market and which are then subjected for drying, extracted using soxhlet apparatus. The extracts were subjected to test the antioxidant activity using DPPH method. From the DPPH assay it was confirmed that the compounds are having antioxidant activity, IC 50 values were also determined. Therefore, pharmacological test is necessary to isolate and characterize their active compounds. Moreover, these plant extracts should be investigated in vivo to better understand their safety, efficacy and properties.
\end{abstract}

Keywords: Ocimum Basilicum; Allium Cepa; Antioxidant; IC 50; DPPH

\section{Introduction}

Studies focused on plant based formulations for treating human ailments contain the constituents of medicinal value which also proves the Functional value of food supplements [1].

Medicinal herbs possess antioxidant properties which protects the cell against the reactive oxygen species Scavenging activity. Many plant based drugs form important source of therapeutic agents because of their easy availability, relatively less expensive and non-toxic nature in comparison to synthetic medicine [2].

Though a vast proportion of the higher plant species have been screened for biologically active compounds, drug discovery from plants should remain an essential component in the search for new medicines and the scientific study of traditional medicines, concerned medicinal plants are thus of great importance.

It has been found by many researchers that there is an inverse association between the mortality from agerelated diseases and the consumption of plant products, which could be due to the presence of various antioxidant compounds, especially, phenolics, which are the most reactive compounds. Oxidative stress is defined as imbalance between oxidants and antioxidants and causes damage in all types of biomolecules like protein, nucleic acid, DNA, and RNA. Hence, the balance between reactive species or free radicals and antioxidants is believed to be a critical concept for maintaining a good biological 


\section{Virology \& Immunology Journal}

system. Antioxidants act as free radical scavengers, reducing agents, quenchers of singlet oxygen molecule, and activators for antioxidative enzyme to suppress the damage induced by free radicals in biological system [2].

Antioxidants present in plant products help in the stimulation of cellular defence system and biological system against oxidative damage [3].

Natural and synthetic antioxidants can inhibit or delay the process of lipid oxidation mediated by prooxidants. Antioxidant acts as a free radical scavenger, reducing agent, chelator, or singlet oxygen scavenger. Numerous synthetic antioxidants have been registered, but only a few species are permitted as food additives by the law because of toxicity effects and other side-effects.

Typical antioxidants permitted as the food additives are butylated hydroxy anisole (BHA), butylated hydroxy toluene (BHT), pueraria glycoside (PG), and tertiarybutylated hydroquinone (TBHQ) [4].

More than 64 plants have been found to possess significant antibacterial properties; and more than 24 plants have been found to possess anti diabetic properties, antimicrobial studies of plants, plant for antidotes activity, 400 traditional plant derived products found managing type 2 diabetes, Several anticancer agents including taxol, vinblastine, vincristine, the camptothecin derivatives, topotecan and irinotecan, and etoposide derived from varied plants [5].

Common phenolic antioxidants from plant sources include flavonoid compounds, cinnamic acid derivatives, coumarins, tocopherols, carotenoids, and polyfunctional organic acids [6].

\section{Allium Cepa (Family: Amaryllidaceae)}

Onions contain low amounts of essential nutrients, are low in fats, (89\% water, $4 \%$ sugar, $1 \%$ protein, $2 \%$ fiber and $0.1 \% \mathrm{fat}$ ) and have an energy value of $166 \mathrm{~kJ}$ ( $40 \mathrm{kcal}$ ) per $100 \mathrm{~g}$. They contribute their flavor to savory dishes without raising caloric content appreciably. Onions contain phytochemical compounds such as phenolics that are under basic research to determine their possible properties in humans [7].

A wide variety of allyl sulfides are found in onion, including the four major diallyl sulfides: DMS (diallyl monosulfide), DDS (diallyl disulfide), DTS (diallyl trisulfide), and DTTS (diallyl tetrasulfide). Also present are a wide variety of sulfoxides, including (+) S-methyl-Lcysteine sulfoxide (MCSO), (+)-S-(1-propenyl)-L-cysteine sulfoxide (PRENCSO), S-methyl-l-cysteine sulfoxide, S- propyl-l-cysteine sulfoxide, and S-propenyl-l-cysteine sulfoxide [8].

- Sulfur compounds in onion can lower blood levels of cholesterol and triglycerides.

- Onions have shown potential for improvement of blood sugar balance.

- It helps in increase our bone density and may be of special benefit to women of menopausal age who are experiencing loss of bone density.

- Onions provide important anti-inflammatory benefits.

- Onion in A, a unique sulfur molecule in onion that is found in the bulb portion of the plant has been shown to inhibit the activity of macrophages, specialized white blood cells that play a key role in our body's immune defense system

- Colorectal cancer, laryngeal cancer, and ovarian cancer are the cancer types for which risk is reduced along with moderate amounts of dietary onion.

\section{Ocimum basilicum (Family: Lamiaceae) (Holy Basil, Krishna Tulsi, Manjari \& Brinda)}

Contains vitamin $\mathrm{C}$ and $\mathrm{A}$, and minerals like calcium, zinc and iron, as well as chlorophyll and many other phytonutrients. Also enhances the efficient digestion, absorption and use of nutrients from food and other herbs. Protein: $30 \mathrm{Kcal}, 4.2 \mathrm{~g}$; Fat: $0.5 \mathrm{~g}$; Carbohydrate 2.3 g; Calcium: $25 \mathrm{mg}$; Phosphorus $287 \mathrm{mg}$; Iron: $15.1 \mathrm{mg}$ and Edible portion $25 \mathrm{mg}$ vitamin C per $100 \mathrm{~g}$ [9].

The dried leaf powder of thulasi contains 49 components, major components were 1-Methyl eugenol (89.20\%), 2-Eugenol (5.29\%), in methanolic extract 1Stigmast-5-en-3-ol (17.46\%), 2-Stigmast-5, 22-dien-3-ol (13.13\%), 3-Methyl eugenol (6.19\%) were found in majority, in acetonic extract 1- Methyl eugenol (25.31\%) and 2-Neophytadiene $(7.77 \%)$ were found in majority, in Petroleum ether extract 1- Methyl eugenol (20.97\%), 2Octadecane (17.50\%), 3- $\beta$-caryophylene $(8.22 \%)$ were found in majority [10]. The leaf volatile oil contains eugenol (1-hydroxy-2-methoxy-4-allylbenzene), euginal (also called eugenic acid), urosolic acid, carvacrol (5isopropyl-2-methylphenol), linalool (3,7-dimethylocta1,6-dien-3-ol), limatrol, caryophyllene, methyl carvicol while the seed volatile oil have fatty acids and sitosterol. Other than these the seed mucilage of Tulsi contains some levels of sugars and green leaves are the source of anthocyans [11].

It improves digestions and helps in flushing out free radicals from our body. It helps in enhancing intake of nutrients into from food. It plays very good role in preventing diarrhea, indigestion and dysentery. Crushed 
basil leaves and mixed with honey and taking this concoction for is very helpful in killing intestinal germs and bacteria and reliving stomach related disorders.

Used in the treatment of common cold and fever.

Used in the treatment of acne.

Used in relieving of headache and stress.

Used for curing mouth ulcers and in the treatment of Asthma, Bronchitis, Tuberculosis etc

It is very good for treatment of eczema, psoriasis and other skin disorders.

It helps in purification of blood by removing free radicals and toxic wastes from our body.

Plant Collection and Extraction: Fresh leaves of Ocimum basilicum are obtained from local area and the fruits of Allium cepa were collected randomly from the shops of Hyderabad, India. They washed twice with double distilled water and the surface sterilized using $70 \%$ ethanol. The peels were shade dried for 3 to 4 weeks. Then the leaves were subjected to drying for about 6-8 days under shade. The top layers of Allium cepa fruit were removed. The dried leaves were subjected to grinding to get uniform fine powder material. The dried leaves and Allium cepa fruits were collected for extraction. Fifty grams of each plant material was weighed in an round bottomed flask to which $250 \mathrm{ml}$ of double distilled water is added for pre-extraction. The round bottomed flask is placed in an assembly of soxhlet extraction apparatus.

Soxhlet extraction was carried out for a period that it has to finish 6 cycles. Extracted plant material collected in round bottomed flask. (The process was carried out separately for Ocimum basilicum leaves and Allium cepa). The extract which contains required chemical constituents was subjected to evaporation process using Rota evaporator for the complete evaporation of solvent material. After the complete evaporation of solvent the powder material was get freed from even tarce amounts of solvents using lyophilliser (BVK Technology services). The pure powder material was subjected to specific tests for compounds using standard procedures $[1-3,6]$.

DPPH Radical Scavenging Activity: The extracted powder was tested for its antioxidant property using DPPH (2, 2- diphenyl-1-picrylhydrazyl) technique. Ocimum extract (only for $35^{\circ} \mathrm{C}$ ) and standard ascorbic acid solution $(0.1 \mathrm{ml})$ of different concentrations viz. 10 , $20,40,60,80$ and $100 \mu \mathrm{g} / \mathrm{ml}$ was added to $3 \mathrm{ml}$ of a $0.004 \%$ methanol (Yarrow chem., Mumbai) solution of DPPH. An equal amount of methanol and DPPH served as control. After 30 minutes incubation in the dark,

\section{Virology \& Immunology Journal}

absorbance was recorded at $517 \mathrm{~nm}$, and the percentage inhibition activity was calculated from equation below:

$$
[(\mathrm{A} 0-\mathrm{A} 1) / \mathrm{A} 0] \times 100
$$

Where $\mathrm{A} 0$ is the absorbance of the control, and

$\mathrm{A} 1$ is the absorbance of the extract/standard.

The antioxidant activity of the extract was expressed as IC50. The IC50 value was defined as the concentration (in $\mu \mathrm{g} / \mathrm{ml}$ ) of extracts that inhibits the formation of DPPH radicals by $50 \%$. All the tests were performed in triplicate and the graph was plotted with the average of three observations hetarct of Allium cepa also.

\section{Results}

Allium cepa alcoholic extract when subjected to phytochemical test indicated the presence of phenolic compounds, triterpenes and fat while Ocimum basilicum aqueous extract was found positive for presence of flavonoids, tannins, alkaloids and Eugenol.

From the DPPH radical scavenging technique it was evident that both the extracts were showing antioxidant activities, as the concentration increases the antioxidant activity also found to be increased. Ascorbic acid served as standard. The results were shown in below tabular column and graphs.

The extracts showed varied levels of DPPH radical scavenging activity at $10,20,40,80,100 \mu \mathrm{g} / \mathrm{mL}$ concentrations. The Standard and extracts produced a dose dependent inhibition of the DPPH radicals.

Both the extracts and standard exhibited strongest DPPH radical scavenging activity. The extracts radical scavenging activity were effective in the order standard > Ocimum basilicum > Allium cepa. The IC50 value of Ocimum basilicum and Allium cepa were found to be $54.2 \%$ and $28.81 \%$ respectively in comparison to the standard ascorbic acid $101.7 \%$.

\section{Antioxidant Properties of Standard Ascorbic Acid Solution}

\begin{tabular}{|c|c|c|c|}
\hline CONC & Ascorbic Acid value & $\begin{array}{c}\text { \% } \\
\text { INHIBITION }\end{array}$ & \multirow{2}{*}{ IC 50 VALUE } \\
\hline 10 & 0.088 & 29.25 & \\
& 0.1 & 26.73 & \multirow{2}{*}{101.7} \\
\hline 40 & 0.121 & 22.33 & \\
\hline 60 & 0.147 & 16.88 & \multirow{2}{*}{} \\
\hline 80 & 0.156 & 14.99 & \\
\hline 100 & 0.17 & 12.06 & \\
\hline
\end{tabular}

Table 1: Standard solution. 


\section{Virology \& Immunology Journal}

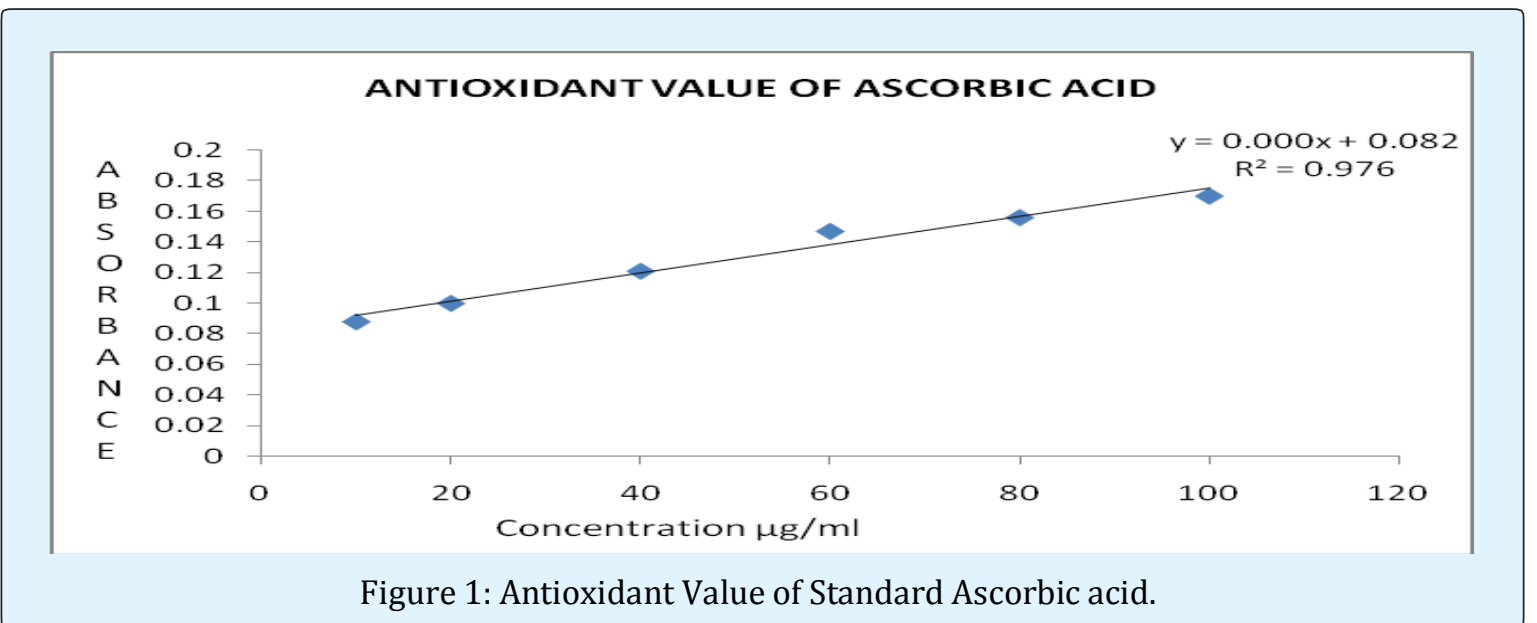

\section{Antioxidant Properties of Ocimum Basilicum}

\begin{tabular}{|c|c|c|c|}
\hline Conc & Ocimum basilicum value & \%INHIBITION & \multirow{2}{*}{ IC50 VALUE } \\
\hline 10 & 0.034 & 40.57 & \multirow{3}{*}{54.22} \\
\hline 20 & 0.068 & 33.44 & \multirow{2}{*}{} \\
\hline 40 & 0.088 & 29.25 & \\
\hline 60 & 0.102 & 26.31 & \\
\hline 80 & 0.116 & 23.38 & \\
\hline 100 & 0.129 & 20.65 & \\
\hline
\end{tabular}

Table 2: Antioxidant Properties of Ocimum basilicum.

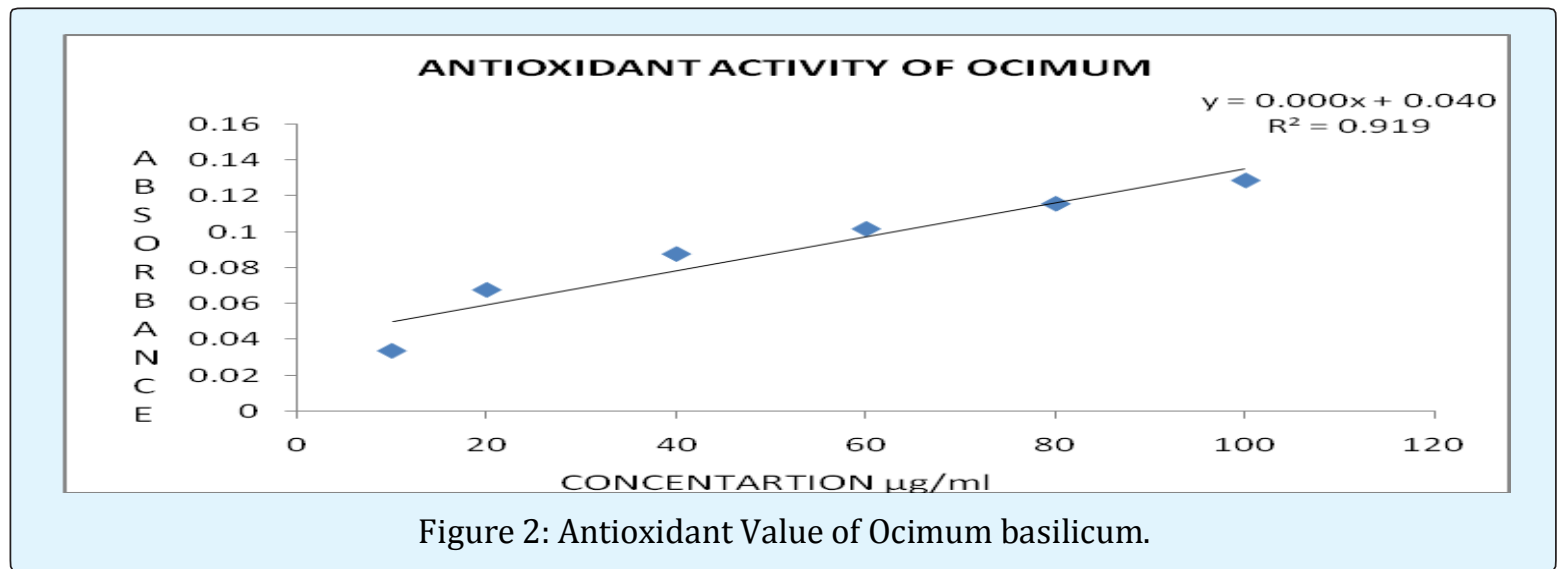

Antioxidant Properties of Allium cepa Solution

\begin{tabular}{|c|c|c|c|}
\hline Conc & Allium cepa Value & \%INHIBITION & \multirow{2}{*}{ IC 50 } \\
\hline 10 & 0.02 & 43.5 & \multirow{2}{*}{28.81} \\
\hline 20 & 0.038 & 39.73 & \\
\hline 60 & 0.049 & 37.42 & \\
\hline 80 & 0.065 & 29.25 & \\
\hline 100 & 0.088 & 26.1 & \\
\hline
\end{tabular}

Table 3: Antioxidant Properties of Allium cepa Solution. 


\section{Virology \& Immunology Journal}

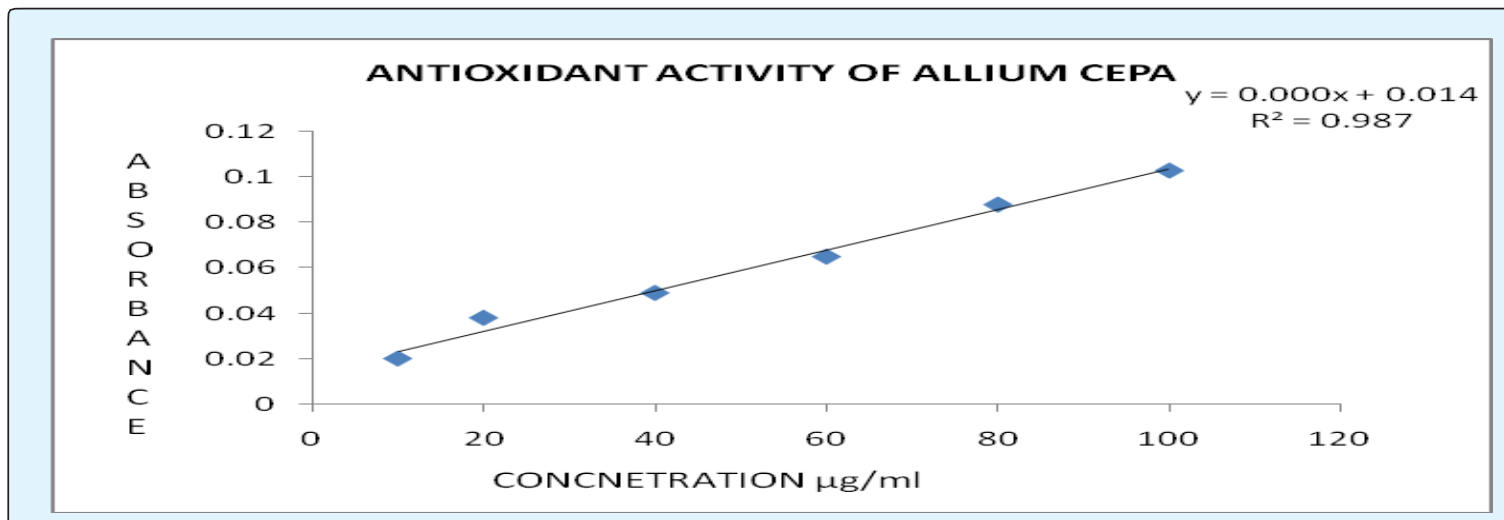

Figure 3: Antioxidant Value of Allium cepa.

\section{Conclusion}

The crude fruits and leaves were collected from local market and which are then subjected for drying, extracted using soxhlet apparatus. The extracts were subjected to test the antioxidant activity using DPPH method. From the DPPH assay it was confirmed that the compounds are having antioxidant activity, IC 50 values were also determined. Therefore, pharmacological test is necessary to isolate and characterize their active compounds. Moreover, these plants extract should be investigated in vivo to better understand their safety, efficacy and properties which could serve as an alternative for novel medicine.

\section{References}

1. Beatovicet D, Krstić-Milošević D, Trifunović S, Šiljegović J, Glamočlija J, et al. (2015) Chemical Composition, Antioxidant and Antimicrobial Activities of the Essential Oils of Twelve Ocimum basilicum L. Cultivars Grown in Serbia. Rec Nat Prod 9(1): 62-75.

2. Londhe AM, Kulkarni AS, Lawand RV (2015) In-Vitro Comparative Study of Antibacterial and Antifungal Activities: A Case Study of Ocimum kilimandscharicum, Ocimum tenuiflorum and Ocimum gratissimum 7(1): 104-110.

3. Manoorkar, Gachande Evaluation of antifungal activity of some medicinal plant extracts against some storage seed -borne fungi of Groundnut.

4. Al-Hajj NQM, Wang HX, Ma C, Lou Z, Bashari M, et al. (2014) Antimicrobial and Antioxidant Activities of the Essential Oils of Some Aromatic Medicinal Plants.
(Pulicaria inuloides-Asteraceae and Ocimum forskolei-Lamiaceae). Tropical Journal of Pharmaceutical Research 13(8): 1287-1293.

5. Fidrianny I, Harnovi M, Insanu M (2014) Evaluation Of Antioxidant Activities From Various Extracts of Sweet Orange Peels Using Dpph, Frap Assays And Correlation With Phenolic, Flavonoid, Carotenoid Content. Asian J Pharm Clin Res 7(3): 186-190.

6. Shaik G, Sujatha N, Mehar SK (2014) Medicinal plants as source of antibacterial agents to counter Klebsiella pneumonia. Journal of Applied Pharmaceutical Science 4(1): 135-147.

7. https://www.pinterest.com/pin/415879965420058 $20 \%$.

8. Tsao SM, Yin MC (2001) In-vitro antimicrobial activity of four diallyl sulphides occurring naturally in garlic and Chinese leek oils. J Med Microbiol 50(7): 646-649.

9. Anbarasu K, Vijayalakshmi G (2007) Improved shelf life of protein-rich tofu using Ocimum sanctum (tulsi) extracts to benefit Indian rural population. J Food Sci 72(8): M300-305.

10. Wagner H, Norr $H$, Winterhoff $H$ (1994) Plant adaptogens. Phyto med 1(1): 63-76.

11. Pattanayak P, Behera P, Das D, Panda SK (2010) Ocimum sanctum Linn. A reservoir plant for therapeutic applications: An overview. Pharmacogn Rev 4(7): 95-105.

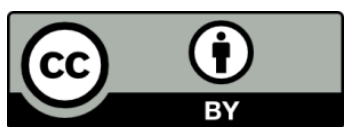

